\title{
International genetic evaluation of Holstein bulls for overall type traits and body condition score
}

\author{
M. Battagin, ${ }^{1}$ F. Forabosco, $†$ J. H. Jakobsen, $†$ M. Penasa, ${ }^{\star}$ T. J. Lawlor,‡ and M. Cassandro* \\ *Department of Agronomy, Food, Natural Resources, Animals and Environment, University of Padova, Viale dell'Università 16, \\ 35020 Legnaro (PD), Italy \\ †Interbull Centre, Department of Animal Breeding and Genetics, SLU, Uppsala, Sweden SE 75007 \\ ¥Holstein Association USA, Brattleboro, VT 05301
}

\section{ABSTRACT}

The study documents the procedures used to estimate genetic correlations among countries for overall conformation (OCS), overall udder (OUS), overall feet and legs (OFL), and body condition score (BCS) of Holstein sires. Major differences in traits definition are discussed, in addition to the use of international breeding values (IBV) among countries involved in international genetic evaluations, and similarities among countries through hierarchical clustering. Data were available for populations from 20 countries for OCS and OUS, 18 populations for OFL, and 11 populations for BCS. The IBV for overall traits and BCS were calculated using a multi-trait across-country evaluation model. Distance measures, obtained from genetic correlations, were used as input values in the cluster analysis. Results from surveys sent to countries participating in international genetic evaluation for conformation traits showed that different ways of defining traits are used: the overall traits were either computed from linear or composite traits or defined as general characteristics. For BCS, populations were divided into 2 groups: one scored and evaluated BCS, and one used a best predictor. In general, populations were well connected except for Estonia and French Red Holstein. The average number of common bulls for the overall traits ranged from 19 (OCS and OUS of French Red Holstein) to 514 (OFL of United States), and for BCS from 17 (French Red Holstein) to 413 (the Netherlands). The average genetic correlation (range) across countries was 0.75 (0.35 to $0.95), 0.80$ (0.41 to 0.95 ), and 0.68 (0.12 to 0.89 ) for OCS, OUS, and OFL, respectively. Genetic correlations among countries that used angularity as best predictor for BCS and countries that scored BCS were negative. The cluster analysis provided a clear picture of the countries distances; differences were due to trait defini-

Received January 12, 2012.

Accepted March 20, 2012.

${ }^{1}$ Corresponding author: mara.battagin@studenti.unipd.it tion, trait composition, and weights in overall traits, genetic ties, and genotype by environment interactions. Harmonization of trait definition and increasing genetic ties could improve genetic correlations across countries and reduce the distances. In each national selection index, all countries, except Estonia and New Zealand, included at least one overall trait, whereas none included BCS. Out of 18 countries, 9 have started genomic evaluation of conformation traits. The first were Canada, France, New Zealand, and United States in 2009, followed by Switzerland, Germany, and the Netherlands in 2010, and Australia and Denmark-Finland-Sweden (joint evaluation) in 2011. Six countries are planning to start soon.

Key words: overall conformation trait, body condition score, international evaluation, cluster analysis

\section{INTRODUCTION}

Conformation was one of the first nonproduction traits scored and included in the selection indices of dairy cattle populations around the world (White, 1974; Powell and Norman, 2006; Shook, 2006). Conformation is often referred to as an early predictor of functional traits, such as longevity, and it is used to reduce the deterioration of health and fertility in dairy (Mark, 2004; Miglior et al., 2005; Shook, 2006), dual-purpose (Sölkner et al., 2000), and beef cows (Forabosco et al., 2004). At a national level, type traits are scored as linear traits, composite traits, or general characteristics. The scoring system for linear traits describes the conformation objectively, from one biological extreme to the other (Shook, 2006), and each trait depicts only one specific part of the cow (ICAR, 2011). Composite traits are groups of linear traits related to one specific area (e.g., frame, dairy strength, udder, feet and legs) and are weighted according to the breeding objective of each country (ICAR, 2011). General characteristics are phenotypic assessments and subjective scores are given for the desirability of the cow according to the national breeding goal (ICAR, 2011). The World Hol- 
stein Friesian Federation (WHFF) and International Committee for Animal Recording (ICAR) established specific guidelines for definition of conformation traits, data recording, genetic evaluation, and publication of type proofs for bulls.

The term "overall traits" will be used hereafter to summarize conformation traits that are not linearly scored and that are internationally evaluated; namely, overall conformation (OCS), overall udder (OUS), and overall feet and legs (OFL).

One of the newest traits recognized by WHFF is BCS, defined as "the covering of fat over the tail head and rump" (WHFF, 2008). Body condition score reflects the degree of apparent adiposity of the cow and it can be used as an indicator of overall energy status; changes in BCS reflect mobilization of adipose tissue stores during lactation (Roche et al., 2009). In addition, BCS is an important management trait in the dairy herd as it can be used as a predictor of the reproduction, health and welfare status of cows (Dal Zotto et al., 2007; Roche et al., 2009; Bastin et al., 2010).

The International Bull Evaluation Service (Interbull, Uppsala, Sweden) was established in 1994 to provide international estimated breeding values (IBV) for dairy bulls. The multiple across-country evaluation (MACE) method, developed by Schaeffer (1994) and refined in the following years (Sigurdsson et al., 1996; Sullivan, 1999; Fikse and Banos, 2001), uses deregressed national EBV as input values to predict IBV for bulls of all participating countries. Interbull is developing methodology to include the genomic information in the evaluation of dairy breeds (VanRaden and Sullivan, 2010; Sullivan et al., 2012; Zumbach et al., 2012).

The first routine international genetic evaluation for conformation traits of Holstein bulls was carried out in 1999 and involved 10 countries. Currently, 19 countries participate in the evaluation that includes 18 linear traits and 3 overall traits (OCS, OUS, and OFL) recorded on 5 breeds (Interbull, 2011b). International genetic evaluation for BCS was added to the service portfolio in January 2009 with data on Holstein bulls from 10 countries (Interbull, 2011b).

Linear traits for the Holstein breed are expected to be similarly defined across countries because of the harmonization process developed by WHFF (Mark, 2004), whereas overall traits are heterogeneous and depend on the specific national breeding goals (Shook, 2006). Recently, countries participating in international genetic evaluations have discussed the efficiency of MACE to evaluate overall traits when those traits are not consistently defined across countries (Canavesi et al., 2006). When trait definitions vary between countries, the genetic correlations are low (Miglior et al., 2004). Then, domestic bulls (or bulls with daughters in a specific country) are favored over foreign bulls (or bulls with only daughters that are not in the specific country; Canavesi et al., 2006). Previous research has suggested the use of linear traits to derive overall traits instead of using general characteristics or subjective scores in international genetic evaluations (Miglior et al., 2004; Canavesi et al., 2006).

The objectives of this study were (1) to report differences and similarities among countries for overall traits (OCS, OUS, and OFL) and BCS in the Holstein breed; (2) to discuss the publication policy and use of IBV at national levels among member organizations involved in the routine international evaluation; and 3) to document the status of genomic evaluation for these traits.

\section{MATERIALS AND METHODS}

\section{National Evaluation Procedures}

A survey on OCS, OUS, OFL, and BCS of Holstein cattle was sent to countries participating in international genetic evaluation. The main aim of the survey was to collect detailed information on composition, computation, and use of overall traits in the selection index, and to document the progress of genomic evaluation in member countries. In addition, supplementary information about the publication policy of the above traits was retrieved.

\section{International Genetic Evaluation}

Data. Twenty populations [Australia (AUS), Belgium (BEL), Canada (CAN), Czech Republic (CZE), Denmark-Finland-Sweden (DFS), Estonia (EST), French Black and White (FRA) and Red (FRR) Holstein, Germany (DEU), Hungary (HUN), Italy (ITA), Japan (JPN), New Zealand (NZL), Spain (ESP), Swiss Black and White (CHE) and Red (CHR) Holstein, Poland (POL), the Netherlands (NLD), the United Kingdom and Ireland (GBR), and the United States (USA)] provided information on Holstein bulls to compute the April 2011 routine international genetic evaluation for OCS and OUS (Table 1). For OFL and BCS, data were from 18 (Table 1) and 11 (Table 2) populations, respectively.

Procedure. International genetic evaluations can be divided into 2 main steps: (1) deregression, within-country sire variance estimation, and correlation estimation between countries; and (2) deregression, within-country sire variance estimation, and breeding value prediction. Step 1 as applied to Holstein conformation traits is described. To be included in the international evaluation, Interbull required country of first test proofs of AI 
Table 1. Information on overall conformation (OCS), overall udder (OUS), and overall feet and legs (OFL) across countries in international genetic evaluations

\begin{tabular}{|c|c|c|c|c|c|c|c|}
\hline \multirow[b]{2}{*}{ Country $^{1}$} & \multicolumn{3}{|c|}{ Classification $^{2}$} & \multirow{2}{*}{$\begin{array}{l}\text { Common } \\
\text { bulls }^{3}\end{array}$} & \multicolumn{3}{|c|}{ Heritability $^{3}$} \\
\hline & OCS & OUS & OFL & & OCS & OUS & OFL \\
\hline AUS & $\mathrm{C}$ & $\mathrm{C}$ & $\mathrm{BP}^{4}$ & 207 & 0.300 & 0.300 & 0.210 \\
\hline BEL & $\mathrm{C}$ & $\mathrm{L}$ & $\mathrm{L}$ & 213 & 0.359 & 0.238 & 0.132 \\
\hline CAN & $\mathrm{C}$ & $\mathrm{L}$ & $\mathrm{L}$ & 361 & 0.261 & 0.247 & 0.152 \\
\hline $\mathrm{CHE}$ & $\mathrm{NA}^{5}$ & NA & NA & 170 & 0.253 & 0.210 & 0.165 \\
\hline CHR & $\mathrm{C}$ & $\mathrm{L}$ & $\mathrm{L}$ & 123 & 0.340 & 0.370 & 0.220 \\
\hline CZE & $\mathrm{C}$ & L & L & 297 & 0.252 & 0.197 & 0.121 \\
\hline DEU & $\mathrm{C}$ & $\mathrm{C}$ & $\mathrm{C}$ & 379 & 0.260 & 0.225 & 0.182 \\
\hline DFS & $\mathrm{L}$ & $\mathrm{L}$ & $\mathrm{L}$ & 343 & 0.300 & 0.250 & 0.200 \\
\hline ESP & $\mathrm{L}$ & $\mathrm{L}$ & $\mathrm{S}$ & 283 & 0.240 & 0.250 & 0.150 \\
\hline EST & $\mathrm{C}$ & $\mathrm{S}$ & $\mathrm{S}$ & 34 & 0.270 & 0.310 & 0.140 \\
\hline FRA & $\mathrm{L}$ & L & $\mathrm{S}$ & 264 & 0.300 & 0.300 & 0.100 \\
\hline FRR & $\mathrm{C}$ & $\mathrm{S}$ & - & 19 & 0.310 & 0.410 & - \\
\hline GBR & $\mathrm{C}$ & $\mathrm{S}$ & $\mathrm{S}$ & 455 & 0.310 & 0.259 & 0.153 \\
\hline HUN & $\mathrm{S}$ & $\mathrm{S}$ & $\mathrm{S}$ & 253 & 0.200 & 0.120 & 0.150 \\
\hline ITA & $\mathrm{L}$ & $\mathrm{L}$ & $\mathrm{C}$ & 423 & 0.240 & 0.280 & 0.100 \\
\hline JPN & $\mathrm{C}$ & $\mathrm{S}$ & $\mathrm{S}$ & 110 & 0.270 & 0.200 & 0.130 \\
\hline NLD & $\mathrm{C}$ & $\mathrm{S}$ & $\mathrm{S}$ & 495 & 0.300 & 0.340 & 0.170 \\
\hline NZL & L & $\mathrm{L}$ & - & 203 & 0.190 & 0.230 & - \\
\hline POL & $\mathrm{L}$ & $\mathrm{L}$ & $\mathrm{L}$ & 250 & 0.280 & 0.150 & 0.100 \\
\hline USA & $\mathrm{C}$ & $\mathrm{L}$ & L & 514 & 0.310 & 0.230 & 0.170 \\
\hline
\end{tabular}

${ }^{1}$ AUS $=$ Australia; BEL = Belgium; CAN = Canada; $\mathrm{CHE}=$ Switzerland (Black and White Holstein); CHR = Switzerland (Red Holstein); CZE = Czech Republic; DEU = Germany; DFS = Denmark-Finland-Sweden; ESP $=$ Spain EST $=$ Estonia; FRA $=$ France $($ Black and White Holstein); FRR $=$ France (Red Holstein); GBR = United Kingdom and Ireland; HUN = Hungary; ITA = Italy; JPN = Japan; NLD = the Netherlands; NZL = New Zealand; POL $=$ Poland; USA $=$ United States.

${ }^{2}$ Method to define traits: $\mathrm{S}=$ subjective; $\mathrm{L}=$ computed from linear traits; $\mathrm{C}=$ computed from a set of composite traits or composite traits and linear traits.

${ }^{3}$ Mean number of common bulls for OCS, OUS, and OFL, and heritability provided by the countries participating in April 2011 international multiple-trait across-country routine evaluation (MACE).

${ }^{4} \mathrm{BP}=$ best predictor.

${ }^{5} \mathrm{NA}=$ not available.

bulls with at least 10 daughters, or 10 effective daughter contributions in at least 10 herds. Only Holstein bulls born from 1970 onward were included for correlation estimation. The quality of international genetic evaluations depends on the quality of national data. For this reason, a national genetic evaluation model for conformation traits must pass the trend validation test (Boichard et al., 1995) for stature and fore udder attachment and be within the limit of $5 \%$ change in sire standard deviation between 2 succeeding official evaluations (Jakobsen and Hjerpe, 2006). In addition, countries are encouraged to verify changes in genetic evaluations (Klei et al., 2002) before submitting data to Interbull. National EBV were first deregressed within country to obtain variables independent of all effects included in the international sire model (Sigurdsson and Banos, 1995). Then, genetic parameters (sire variance within country and genetic correlations between countries) were estimated by Interbull at the test run in January 2011, with the expectation maximization (EM) algorithm for REML procedure described by Klei and Weigel (1998).
Because of computational limits, genetic correlations were estimated from subsets of data, and at most 10 countries at a time were included, using only bulls that had multiple proofs in different countries plus full-sibs or three-quarter sibs of such bulls. Countries were grouped into triplets, with the USA as the link between any other 2 groups. Genetic correlations for all country pairs were estimated by considering all possible combinations of triplets.

Heritability values used for the international evaluations were those provided by the countries. Pedigree was traced back as far as possible to increase acrosscountry connections. Genetic groups for unidentified parents were defined according to national origin, breed and birth year of the bull, and path of selection (sires, maternal grandsires, and maternal granddams). Minimum group size was set to 30 (Interbull, 2011b).

\section{Cluster Analysis}

Data used in the cluster analysis consisted of acrosscountry genetic correlations estimated by Interbull dur- 
Table 2. Information on BCS across countries

\begin{tabular}{|c|c|c|c|c|c|c|}
\hline \multirow[b]{2}{*}{ Country $^{1}$} & \multirow[b]{2}{*}{ Trait definition } & \multirow{2}{*}{$\begin{array}{l}\text { Data } \\
\text { since }\end{array}$} & \multicolumn{2}{|c|}{ Evaluation $^{2}$} & \multirow{2}{*}{$\begin{array}{l}\text { Common } \\
\text { bulls }^{3}\end{array}$} & \multirow[b]{2}{*}{ Heritability $^{3}$} \\
\hline & & & $\mathrm{N}$ & INT & & \\
\hline$\overline{\text { AUS }}$ & Covering of fat over the tail head and rump & $\mathrm{NA}^{4}$ & & & & \\
\hline $\mathrm{CHE}$ & Linear score (Edmonson et al., 1989) & 1992 & $x$ & $x$ & 135 & 0.171 \\
\hline CHR & Covering of fat over the tail head and rump & 2005 & & & & \\
\hline $\mathrm{CZE}$ & Covering of fat over the tail head and rump & 2006 & $x$ & $x$ & 195 & 0.275 \\
\hline EST & Covering of fat over the tail head and rump & 2008 & & & & \\
\hline FRA & Subjective visual assessment & 2009 & $\times$ & $\mathrm{BP}$ & 225 & 0.280 \\
\hline FRR & & & & $\mathrm{BP}$ & 17 & 0.360 \\
\hline GBR & Relative fatness or body condition of the cow & 1996 & $x$ & $\times$ & 377 & 0.268 \\
\hline HUN & NA & 2005 & & & & \\
\hline ITA & Pelvic and lumbar region & 2007 & & $\mathrm{BP}$ & NA & 0.230 \\
\hline
\end{tabular}

${ }^{1}$ AUS = Australia; BEL = Belgium; CHE = Switzerland (Black and White Holstein); CHR = Switzerland (Red Holstein); CZE = Czech Republic; DEU = Germany; DFS = Denmark-Finland-Sweden; ESP = Spain; EST = Estonia; FRA = France (Black and White Holstein); FRR $=$ France (Red Holstein); GBR = United Kingdom and Ireland; HUN = Hungary; ITA = Italy; JPN = Japan; NLD = the Netherlands; NZL $=$ New Zealand; POL $=$ Poland; USA = United States.

${ }^{2} \times=$ countries that had national $(\mathrm{N})$ or international (INT) evaluation for BCS; BP $=$ countries that used a best predictor.

${ }^{3}$ Mean number of common bulls for BCS and heritability provided by the countries participating in April 2011 international multiple-trait across-country routine evaluation (MACE)..

${ }^{4} \mathrm{NA}=$ not available.

${ }^{5}$ Only Denmark evaluated BCS.

ing the January 2011 test run and used for the April 2011 routine genetic evaluation (Interbull, 2011a). Hierarchical clustering was performed using the CLUSTER procedure (SAS Institute, 2008) to visualize the similarity between countries for OCS, OUS, OFL, and BCS. The distance $\left(d_{i j}\right)$ between countries $i$ and $j$ was calculated as $d_{i j}=1-r G_{i j}^{2}$, where $r G_{i j}$ is the genetic correlation between countries $i$ and $j$. Dendrograms were plotted using the TREE procedure (SAS Institute, 2008).

\section{RESULTS AND DISCUSSION}

\section{Trait Definition}

Overall Conformation. Out of 20 populations, 12 included composite traits, 6 used linear traits, and only 1 subjectively described the OCS (Table 1 ). The most common traits used in the composition of OCS were OUS and OFL (Table 3). The weight of OUS and OFL ranged from 30 to $50 \%$ and from 15 to $35 \%$, respectively (data not shown). Dairy strength was adopted by 4 populations and given a weight ranging from 10 to $25 \%$; 3 populations used overall dairy type (from 10 to $30 \%$ of weight) and frame (from 15 to $25 \%$ ). Other traits included in the composition were overall body including rump, overall teats, aspect, front and capacity, and overall development (Table 3).

Among the 18 linear traits evaluated by Interbull (Interbull, 2011b), only BCS was not included by any population, whereas 2 traits that were not internationally evaluated were used: chest depth and topline. Both ITA and ESP used 15 linear traits, followed by FRA (10), DFS (7), and POL (3). The most common traits were rump width, followed by rump angle, angularity, and stature (Table 3 ).

The differences in OCS definition led to differences in how countries publish the IBV for this trait (Miglior et al., 2007). For example, GBR had 2 OCS, 1 for domestic and 1 for international use. The GBR international index for OCS is linearly composed of several type traits and it is a good predictor of the US index for OCS. Since 2004, CAN has adopted a blending approach for IBV of overall traits, which optimizes the use of all information from Interbull evaluations (Miglior et al., 2004).

Overall Udder. Out of 20 populations, 11 computed OUS from linear traits, 2 used composite traits, and 6 
Table 3. Traits used by countries for the definition of overall conformation (OCS), overall udder (OUS), and overall feet and legs (OFL)

\begin{tabular}{|c|c|c|c|}
\hline \multirow[b]{2}{*}{ Country $^{1}$} & \multicolumn{3}{|c|}{ Trait $^{2}$} \\
\hline & OCS & OUS & OFL \\
\hline BEL & ODE, ODT, OFL, ORU, OUS & $\begin{array}{l}\text { FTP, FUA, RTP, RUH, RUW, TLN, } \\
\text { UBL, UDT, USP, UTX }\end{array}$ & BNQ, FAN, RLR, RLS \\
\hline CAN & DST, OFL, ORU, OUS & $\begin{array}{l}\text { UDT, UTX, USP, FUA, FTP, RUH, RUW, } \\
\text { RTP, TLN, and defective characteristics }\end{array}$ & $\begin{array}{l}\text { FAN, HDT, BNQ, RLF, RLR, and } \\
\text { defective characteristics }\end{array}$ \\
\hline $\mathrm{CHR}$ & OFL, ORT, OTE, OUS & FUA, FUL, RUH, UDT, USP, UTX & FAN, HHF, HKQ, LOC, RLR, RLS \\
\hline CZE & DST, FRM, OFL, OUS & FTP, FUA, RTP, RUH, TLN, UDT, USP, UWD & BDQ, FAN, LOC, RLR, RLS \\
\hline DEU & OBR, ODT, OFL, OUS & FTP, FUA, RTP, RUH, TLN, UDT, USC, USP & FAN, FLS, HKQ, LOC, RLR, RLS \\
\hline DFS & ANG, BDP, CWD, RAN, RWD, STA, TOP & FTP, FUA, RTP, RUH, TLN, TTK, UBL, UDT, USP & BNQ, FAN, HKQ, RLR, RLS \\
\hline ESP & $\begin{array}{l}\text { ANG, BDP, CWD, FAN, FTP, FUA, RAN, RLR, } \\
\text { RLS, RUH, RWD, STA, TLN, UDT, USP }\end{array}$ & FTP, FUA, RUH, UDT, USP & Visual assessment of animals \\
\hline EST & OFL, OUS & WHFF & WHFF \\
\hline FRA & $\begin{array}{l}\text { CDP, FTP, LOC, RTP, RUH, RWD, } \\
\text { STA, TLN, UDT, USP }\end{array}$ & FTP, RTP, RUH, TLN, UDT, USP & Visual assessment of locomotion \\
\hline FRR & ASP, OUS & Visual assessment of animals & - \\
\hline GBR & LON, OFL, OUS & $\begin{array}{l}\text { Strength and quality of the fore and rear udder } \\
\text { attachment, strength of central ligament, udder texture }\end{array}$ & $\begin{array}{l}\text { Shape and quality of legs and feet, } \\
\text { resulting in good locomotion }\end{array}$ \\
\hline ITA & $\begin{array}{l}\text { ANG, BDP, CWD, FAN, FTP, FUA, LOC, RAN, } \\
\text { RLR, RLS, RUH, RWD, STA, UDT, USP }\end{array}$ & FTP, FUA, RUH, UDT, USP & FLF, HHD, RLR, RLS \\
\hline JPN & DST, FRM, OFL, OUS & $\begin{array}{l}\text { Udder being strongly attached and fully capacious, } \\
\text { and quarters well-balanced, fine texture }\end{array}$ & $\begin{array}{l}\text { Length well proportioned with the depth } \\
\text { of body, standing wide apart, clean-cut } \\
\text { and strong with light and sound walk }\end{array}$ \\
\hline NLD & DST, FRM, OFL, OUS & Overall judgment of the udder. & Overall judgment of feet and legs \\
\hline NZL & $\begin{array}{l}\text { Traits pertaining dairy conformation } \\
\text { including those body linear traits }\end{array}$ & $\begin{array}{l}\text { Traits pertaining to the udder including } \\
\text { those udder linear traits }\end{array}$ & - \\
\hline POL & ANG, RAN, RWD & FTP, FUA, RUH, TLN, UDT, USP, UWD & FAN, RLR, RLS \\
\hline USA & DST, F\&C, OFL, ORU, OUS & FTP, FUA, RTP, RUH, RUW, UDT, USP & FAN, LOC, RLR, RLS \\
\hline
\end{tabular}

co $\quad{ }^{1} \mathrm{BEL}=$ Belgium; CAN = Canada; CHR = Switzerland (Red Holstein); CZE = Czech Republic; DEU = Germany; DFS = Denmark-Finland-Sweden; ESP = Spain; EST = Estonia; FRA = France (Black and White); FRR = France (Red Holstein); GBR = United Kingdom and Ireland; ITA = Italy; JPN = Japan; NLD = the Netherlands; NZL = New Zealand; @ $\mathrm{POL}=$ Poland; USA $=$ United States.

$\stackrel{2}{\mathrm{O}}{ }^{2} \mathrm{ANG}=$ angularity; $\mathrm{ASP}=$ aspect; $\mathrm{BDP}=$ body depth; BDQ = body quality; BNQ = bone quality; CDP = chest depth; CWD = chest width; DST = dairy strength; F\&C = front and capacity; FAN = foot angle; FLF = feet and legs functionality; FLS = feet and legs score; FRM = frame; FTP = front teat placement; FUA = fore udder; FUL = fore ₹. udder length; HDT = heel depth; HHD = hoof depth; HHF = height of hoof; HKQ = hock quality; LOC = locomotion; LON = longevity; OBR = overall body including rump; ஸी. ODE = overall development; ODT = overall dairy traits; OFL = overall feet and legs; ORU = overall rump; OTE = overall teats; OUS = overall udder; RAN = rump angle; RLR feet and legs; STA = stature; TLN = teat length; TOP $=$ topline; TTK $=$ teat thickness; UBL $=$ udder balance; UDT $=$ udder depth; USC $=$ udder score; USP $=$ udder support; UTX $=$ udder texture; UWD $=$ udder width; $\mathrm{WHFF}=$ World Holstein Friesian Federation definition. 
assessed OUS subjectively as visual judgment of overall udder (Table 1). All linear traits related to udder and evaluated by Interbull (Interbull, 2011b) were included in the computation. Udder depth, rear udder height, and udder support were included by 10 populations, front teat placement and fore udder attachment by 8 , and rear teat placement and teat length by 5 (Table 3 ). In addition, other traits were used that are not internationally evaluated; namely, udder width, rear udder width, udder texture, udder balance, fore udder length, and teat thickness (Table 3). Overall udder in DEU is a combination of a subjective score ( $25 \%$ of the weight) and linear traits evaluated by Interbull $(75 \%$ of the weight; Table 3). Despite the differences in the OUS composition, this trait was quite homogeneous. Countries that composed OUS by linear traits gave from 15 to $45 \%$ of weight to udder depth, 10 to $22 \%$ to udder support, and 10 to $20 \%$ to rear udder height. Among countries that assessed OUS subjectively, FRR and NLD referred to an overall visual judgment of udder, and GBR and JPN focused attention on the strength and quality of the fore and rear udder attachments and of the central ligament and on udder texture.

Overall Feet and Legs. Neither FRR nor NZL evaluated OFL. Of the remaining 18 populations, 7 computed OFL using linear traits, 2 using composite traits, 7 scored this trait subjectively, and 1 used a best predictor (Table 1). When OFL was composed of linear traits, rear leg set side view, rear leg set rear view, and foot angle traits were used by 6 populations, and locomotion by 3 (Table 3). To assess OFL, other traits not evaluated by Interbull were used; namely, hock quality, bone quality, body quality, and height of hoof (Table 3). Canada included defective characteristics in its composition of OFL (Holstein Canada, 2011). Two countries (ITA and DEU) combined subjective measurements with linear traits and they gave 50 to $55 \%$ of weight to functionality of feet and legs (ITA) and feet and legs score (DEU). Linear traits included by these countries were rear leg set side view, rear leg set rear view (ITA and DEU), foot angle (DEU), locomotion, hock quality (DEU), and hoof depth (ITA; Table 3). When OFL was assessed as a general characteristic, locomotion was recorded by FRA and GBR, whereas JPN evaluated the length of legs in relation to the depth of body, standing wide apart, clean-cut and strong with light and sound walk. Both NLD and ESP gave an overall judgment of feet and legs, whereas AUS did not evaluate OFL nationally and sent to Interbull "side view foot diagonal" as a best predictor.

$\boldsymbol{B C S}$. Body condition score is one of the newest traits evaluated by Interbull and is defined by WHFF as "the covering of fat over the tail head and rump" (ICAR,
2011). Table 2 lists the populations that took part in the international evaluation for BCS as well as populations that did not send BCS data to Interbull but had recordings of the trait or had only national evaluation. Out of 11 populations that have international evaluation, 5 used the WHFF definition to describe this trait, 1 described BCS as "the relative fatness or body condition of the cow," 1 used the linear scale of Edmonson et al. (1989), and 4 used best predictors: angularity (FRA and ITA), opposite of angularity (USA), and muscularity (FRR). Angularity was defined differently by FRA, ITA, and USA; FRA used a "subjective visual assessment of animals," ITA followed the definition of WHFF (the angle and spring of the ribs), and USA the sharpness and flatness of bone. Muscularity is intended by FRR as the opposite of angularity. Out of the 8 populations that did not participate in international evaluation for BCS, 6 defined the trait as indicated by WHFF, 1 (NZL) used a visual estimate of cow body fat reserves, and 1 (HUN) had no information available (Table 2).

\section{Genetic Ties}

Genetic ties among populations are an important factor when estimating genetic correlations, and an increase in the number of common bulls increases the precision of the estimation (Interbull, 2011c). Generally populations were well connected, except for EST and FRR. The average number of common bulls for the overall traits ranged from 19 (OCS and OUS of FRR) to 514 (OFL of USA), and for BCS from 17 (FRR) to 413 (NLD). For overall traits, the strongest connection, on average, was between USA and CAN $(1,216)$, USA and GBR (986), and USA and NLD (968). For BCS, the highest numbers of common bulls were between USA and GBR (918), USA and NLD (738), and GBR and NLD (725).

\section{Heritability and Genetic Correlation}

Heritabilities, as provided by the national evaluation centers (Tables 1 and 2), ranged from 0.190 (NZL) to 0.359 (BEL) for OCS, 0.120 (HUN) to 0.410 (FRR) for OUS, 0.100 (FRA, ITA and POL) to 0.220 (CHR) for OFL, and 0.171 (CHE) to 0.370 (BEL) for BCS.

The matrices of across-countries genetic correlations are available on the Interbull website (Interbull, 2011a). The average genetic correlation across countries was $0.75,0.80$, and 0.68 for OCS, OUS, and OFL, respectively. For OCS, values ranged from 0.35 (POL-NZL) to 0.95 (CHE-CHR); the populations with the highest and the lowest average estimates were GBR (0.83) and 
POL (0.61), respectively. Genetic correlations for OUS ranged from 0.41 (AUS-DFS) to 0.95 (CAN-CHE/ USA); the highest and lowest average estimates were 0.87 (CHE and USA) and 0.63 (POL), respectively. For OFL, genetic correlations ranged from 0.12 (AUSDFS) to 0.89 (CHE-CHR), and the highest and lowest average estimates were 0.75 (USA) and 0.35 (AUS), respectively. Genetic correlations for BCS showed negative values between populations that used angularity as best predictor (FRA, ITA, USA) and populations that scored BCS (CHE, CZE, DEU, DFS, GBR, and NLD). The negative correlations were due to differences in trait definitions; that is, BCS had low scores for skinny cows and high scores for fat cows, whereas angularity had low values for cows that lacked angularity and high values for those with very angular and open ribs. The FRR population was positively correlated with populations that scored BCS because this country uses muscularity as best predictor. Genetic correlations ranged from -0.50 (DFS-FRA) to 0.95 (CHE-NLD and DEU-CZE/NLD). The average genetic correlation in absolute value was 0.77 , with the highest estimate for CZE, DEU, and NLD (0.82) and the lowest for FRA (0.64).

Across-country genetic correlations were less than unity for several reasons: different origins of the data and trait definitions, interaction between genotype and country-environment, differences in national genetic procedures, weak genetic ties, and erroneous identification of bulls between countries (Mark, 2004).

\section{Cluster Analysis}

Overall Conformation. Figure 1a depicts the dendrogram of OCS: AUS, NZL, and POL were the most distant from the rest of the countries. Australia and NZL were grouped in the same cluster, probably because the environment and the production systems are alike, leading to similar breeding goals, and because of the high number of common bulls. The high distance of POL could be explained by a difference in trait definition, as only 3 linear traits were used in the composition of OCS (Table 3 ), and by the relative low number of bull ties (on average, 234 common bulls). Three of the main clusters linked are CZE, HUN, EST (first cluster); DEU, GBR, NLD, USA and DFS (second cluster); and ESP, FRA, ITA (third cluster). All those populations, except HUN, defined OCS from linear or composite traits (Table 1); CZE, EST, DEU, GBR, NLD, and USA gave 35 to $40 \%$ of weight to OUS and 15 to $30 \%$ to OFL. The DFS population did not include traits related to udder and feet and legs in the computation of OCS, and could be tied with these populations because of the high number of common bulls, which ranged from 506 (DEU) to 724 (NLD). The populations with the highest number of linear traits included in the computation were ESP, ITA, and FRA (Table 3).

The 2 Swiss populations, Black and White (CHE) and Red and White (CHR), were the 2 most similar for OCS, probably because they have common ancestors, and they were linked to CAN and JPN. The definition of OCS for CAN and CHR was similar (Table 3), whereas JPN defined OCS as did CZE and NLD, with small difference on the weights, but showed the highest genetic correlations with CHE (0.91), CHR (0.89), and CAN (0.91). Another branch of the dendrogram was composed of BEL and FRR. They gave different definitions of OCS (Table 3), but "aspect" of FRR was a general trait that could include the traits computed by BEL; moreover, the number of Red and White bulls in BEL was high, which could explain the similarity with FRR population. The cluster analysis for OCS shows that countries with similar trait definition are usually linked, but the number of common bulls also influences the position of a country in the genetic tree.

Overall Udder. The cluster of OUS (Figure 1b) showed 2 main branches. In the first branch, POL, AUS, and NZL were the most distant countries. The high distance of POL is due to very low genetic correlations between POL and the other populations, which ranged from 0.55 (FRA) to 0.73 (DEU). Trait definition of POL is similar to that of the countries that defined OUS from linear traits (Table 3). Australia and NZL were better linked to other countries for this trait than for OCS, and DEU could be linked with NLD because of the high number of common bulls and with GBR because of the similarity of trait definition: the traits that DEU used in the computation were related to the subjective definition that GBR gave (Table 3). Canada and CHE showed the lowest distances and were linked with USA and JPN. The trait definition was similar for CAN (Holstein Canada, 2011) and JPN, and related to the linear traits used by USA (Table 3).

The second branch was composed of BEL, CHR, FRR, linked with CZE, HUN, ESP, ITA, and DFS, EST and FRA. The red populations (CHR and FRR) are in the same cluster with BEL. The high number of Red and White bulls in BEL could explain the similarity with CHR and FRR. Both ITA and ESP used the same linear traits (Table 3) and they were linked with CZE and HUN. Population CZE computed OUS using the same traits of ITA and ESP, with the addition of 3 other traits (udder width, fore udder attachment, and teat length). Hungary was linked with CZE and ITA because of the high number of common bulls. Denmark- 
a) OCS

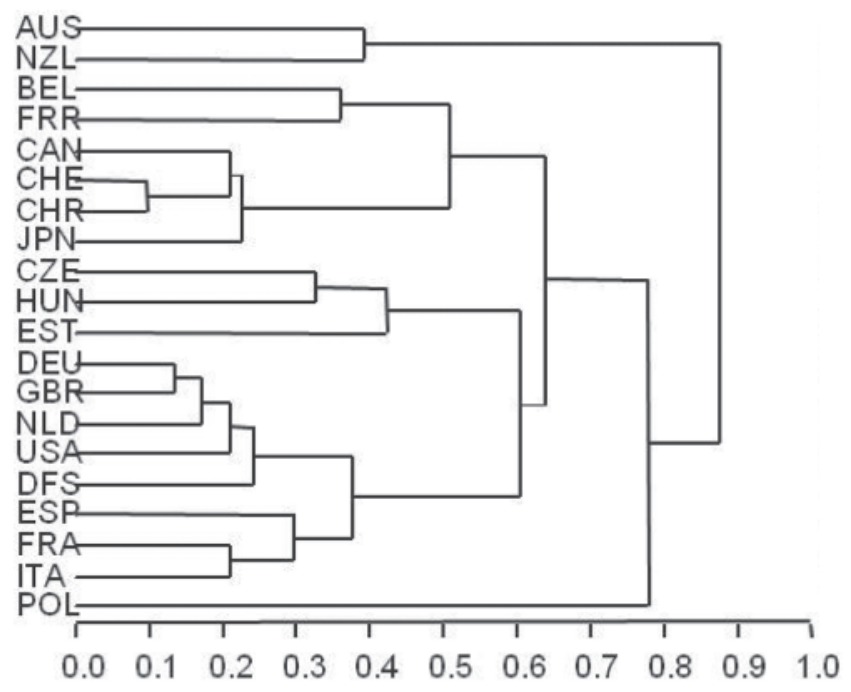

c) OFL

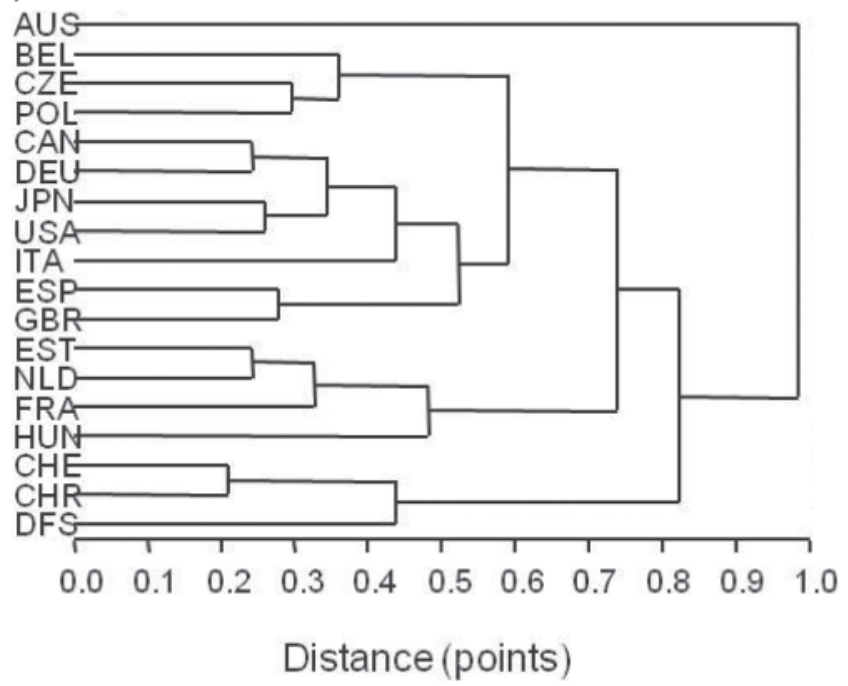

b) OUS

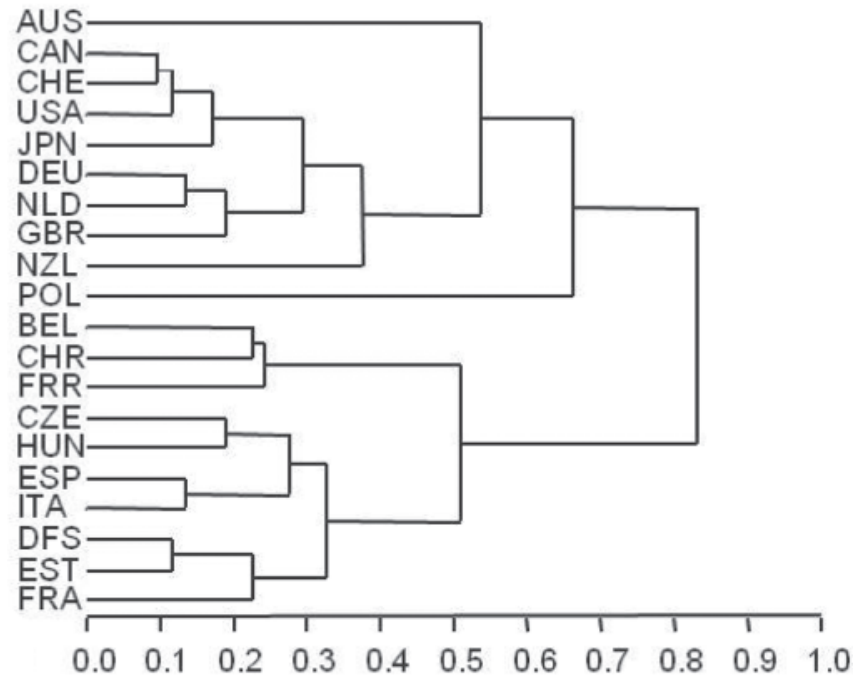

d) BCS

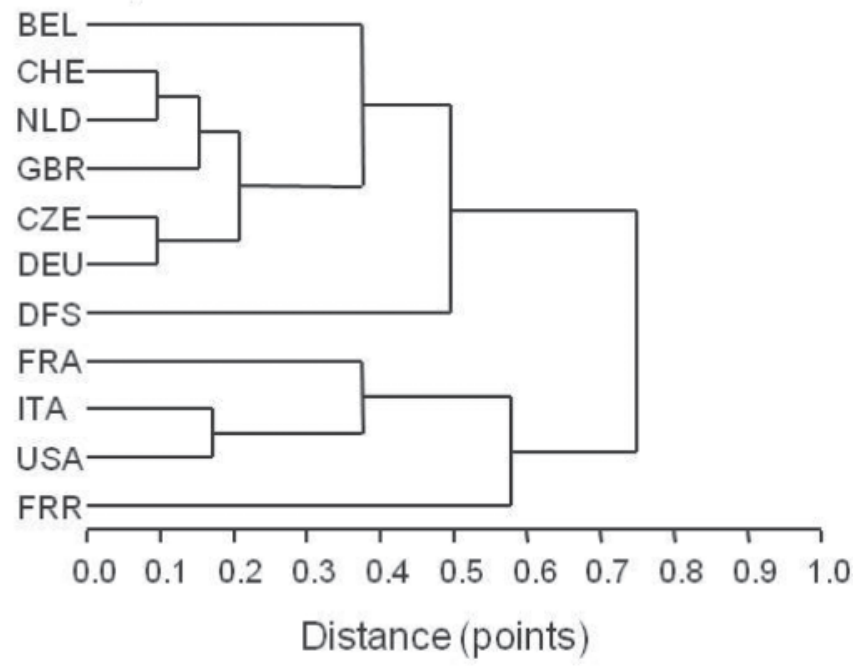

Figure 1. Dendrograms from cluster analysis of (a) overall conformation (OCS), (b) overall udder (OUS), (c) overall feet and legs (OFL) and (d) BCS, using distances calculated from genetic correlations among countries for the April 2011 Interbull (Uppsala, Sweden) routine evaluation for Holstein breed. Countries: AUS = Australia; BEL = Belgium; CAN = Canada; $\mathrm{CHE}=$ Switzerland (Black and White Holstein); CHR = Switzerland (Red Holstein); CZE = Czech Republic; DEU = Germany; DFS = Denmark-Finland-Sweden; ESP = Spain; EST = Estonia; FRA $=$ France $($ Black and White Holstein); FRR = France (Red Holstein); GBR = United Kingdom and Ireland; HUN = Hungary; ITA = Italy; $\mathrm{JPN}=$ Japan; NLD $=$ the Netherlands; NZL $=$ New Zealand; POL $=$ Poland; USA $=$ United States.

Finland-Sweden and EST were very similar: DFS used linear traits in the computation, whereas EST used a subjective description. The FRA population had the highest genetic correlation with DFS and composed OUS using linear traits similar to those used by DFS (Table 3).

Among overall traits, the average genetic correlation across countries was highest for OUS, suggesting a good harmonization in trait definition. We did not, however, observe a clear distinction between populations that defined OUS from linear traits and populations that used a subjective scoring.

Overall Feet and Legs. The most distant population in the cluster of OFL (Figure 1c) was AUS, followed by the cluster of CHE, CHR, and DFS. Australia used "side view foot diagonal" as the best predictor of OFL, whereas CHE, CHR, and DFS computed OFL from linear traits. The similarity of traits used could 
explain the link between DFS and the 2 Swiss populations. Populations that defined OFL subjectively (i.e., EST, NLD, FRA, and HUN) were grouped in one cluster (Table 3). Another branch was formed by BEL, CZE, and POL. They used a composition of linear traits with small differences among populations (Table $3)$. The FRR population did not have an international evaluation of OFL; thus BEL, clustered with FRR for OCS and OUS, changed cluster for OFL.

Spain had the highest number of common bulls with GBR (516); ITA followed the GBR and ESP pair, and it was linked to JPN, USA, CAN, and DEU. Japan defined OFL subjectively, whereas USA gave $50 \%$ of the weight to locomotion, ITA and DEU gave $50 \%$ of the weight to "feet and legs score" and "feet and legs functionality," and CAN used linear traits, respectively (Table 3).

Compared with OCS and OUS, OFL showed the highest distance between countries. Trait definition influenced this higher distance because the "subjectivity" in trait definition was more pronounced.

$\boldsymbol{B C S}$. As reported in the paragraph on trait definition, we observed 2 groups of populations that participated in international evaluation for BCS, 1 that scored and used BCS, and 1 that used a best predictor (Table $2)$. This distinction is clearly depicted by the cluster analysis (Figure 1d). Italy, USA, and FRA, all using angularity as the best predictor, had a maximum distance of 0.38 ; FRR was the most distant due to the use of muscularity. The other branch was composed of DFS and BEL, followed by GBR, NLD, CHE, and CZE, and DEU having DFS as the most distant of this group. Of the 3 countries that comprised DFS, only Denmark sent data for BCS evaluation. Our results for BCS were comparable to those of the pilot study conducted by Lawlor and Klei (2008); in their work, BEL was linked with USA in the cluster of populations that used a best predictor, but since August 2010 the genetic evaluation of BCS in BEL was modified (Interbull, 2011b), which could explain the different allocation of this population.

\section{Selection Indices}

Out of 18 populations, 16 included at least one overall trait in its own selection index, whereas no population included BCS. Out of these 16 populations, 8 included OCS, 11 included OUS, and 12 included OFL. Australia, CHR, FRA, and FRR included only OCS; CZE included only OFL; DEU, DFS, ESP, GBR, HUN, JPN, and NLD included OUS and OFL; and the other populations (BEL, ITA, POL, and USA) included all overall traits. The dynamism of the selection index leads to a reduction of the emphasis of production traits, which ranged from 60 to $100 \%$ in the study of Leitch (1994), increasing the importance of durability, health, and reproduction traits. Within durability, conformation traits provided the largest contribution (Miglior et al., 2005).

The major reasons for including OCS in the selection index were to improve functional traits (Sewalem et al., 2004) and increase height (FRA, FRR), because of the influence on survival (AUS) and lifetime profitability (BEL), positive correlation with longevity (CHE), breeders' desire for a balance of type and production (ITA), as an important subindex in sire of dam selection (POL), and for profit (USA). The OUS and OFL traits were included in the selection index mainly to improve longevity (DFS, ESP, GBR, ITA), to improve lifetime profitability (BEL) and productivity (JPN), for breeders' desire (ESP, NLD), for profit (USA) and cost reduction (DFS), to improve functional traits (DEU, ITA) and workability (DFS), and as an important subindex in sire of dam selection (POL). Moreover, OUS was important to prevent pathologies of udder (ESP, GBR, ITA), and OFL as a good predictor of feet and leg problems [e.g., lameness and digital dermatitis (GBR)] and because of the relationship with fertility (ITA). The survey answers confirmed the importance of conformation to improve functional herd life; that is, the ability of the cow to delay involuntary culling (Schneider et al., 2003) despite longevity being included in the selection index (Forabosco et al., 2009).

\section{Publication of Overall Traits}

Most member countries published EBV for overall traits both in magazines and on websites (12 for OCS, 13 for OUS, 11 for OFL), whereas 5, 4, and 3 published EBV only on websites for OCS, OUS, and OFL, respectively, and 1 country published the EBV only in magazines. The EBV for BCS was published on websites by 6 populations, and 2 published both on websites and in magazines. The majority of populations published the EBV 3 times per year (10 populations for OCS and OUS, 9 for OFL, and 5 for BCS), whereas 3 populations (OCS and OUS), 2 populations (OFL), and 1 population (BCS) published the EBV 2 times per year. The remaining populations published EBV more than 3 times per year.

\section{Genomic Evaluation}

Among 20 populations, 10 have started using genomic evaluation of conformation traits. The first populations (CAN, FRA, FRR, NZL, and USA) started in 2009, followed by CHE, DEU, and NLD in 2010 and AUS 
and DFS in 2011. Six populations are planning to start genomic evaluation soon (CZE, ESP, GBR, ITA, JPN, and POL). Different methods are used by countries to combine genomic breeding values and genomic reliabilities. Genomic evaluation for conformation is likely to change rapidly and a new survey in a few years would probably give very different results.

\section{CONCLUSIONS}

Across-country genetic correlations are useful in evaluating differences among countries, and cluster analysis contributes to the interpretation of the correlation matrix. Genetic correlations were always $<1$, which could be the consequence of different origins of the data and trait definition, interaction between genotype and country-environment, differences in national genetic procedures, weak genetic ties, and erroneous identification of bulls between countries. The differences for overall traits were mostly due to the heterogeneity in trait definitions as countries use linear traits, composite traits, or a subjective description. For BCS, the differences were due to the use of angularity and muscularity as best predictors. The international organizations ICAR and WHFF have developed guidelines for trait definitions for the linear traits that are widely used all over the world, whereas no guidelines have yet been developed for the composite traits. Overall traits are important in selection indices to improve functional traits, and their definition depends on the specific breeding goals in each country. It may be advantageous for national evaluation centers to follow international standards in computing their own overall traits from the MACE linear traits instead of using overall traits with no international standards. National genomic evaluation for type traits has been adopted by some countries and other members are planning to adopt it in the near future. At the international level, Interbull is developing the methodology required to provide international comparisons of genomically enhanced breeding values to member organizations.

\section{ACKNOWLEDGMENTS}

The authors are grateful to the national dairy cattle associations for providing information on conformation traits. The first author thanks the Interbull Centre team for its support and the "Fondazione Ing. Aldo Gini" of Padova for funding the research period at Interbull Centre (Uppsala, Sweden). The useful comments and suggestions provided by 3 anonymous reviewers are gratefully acknowledged.

\section{REFERENCES}

Bastin, C., S. Loker, N. Gengler, A. Sewalem, and F. Miglior. 2010 Genetic relationship between calving traits and body condition score before and after calving in Canadian Ayrshire second-parity cows. J. Dairy Sci. 93:4398-4403.

Boichard, D., B. Bonaiti, A. Barbat, and S. Mattalia. 1995. Three methods to validate the estimation of genetic trend for dairy cattle. J. Dairy Sci. 78:431-437.

Canavesi, F., J. Pena, and G. de Jong. S. Rensing, G. Pedersen Aamand, and S. Mattalia. 2006. Composite traits and international genetic evaluation. Pages $110-117$ in Proc. 35th International Committee on Animal Recording (ICAR) meeting, Koupio, Finland. ICAR, Rome, Italy.

Dal Zotto, R., M. De Marchi, C. Dalvit, M. Cassandro, L. Gallo, P. Carnier, and G. Bittante. 2007. Heritabilities and genetic correlations of body condition score and calving interval with yield, somatic cell score, and linear type traits in Brown Swiss cattle. J. Dairy Sci. 90:5737-5743.

Edmonson, A. J., I. J. Lean, L. D. Weaver, T. Farver, and G. Webster 1989. A body condition scoring chart for Holstein dairy cows. J Dairy Sci. 72:68-78.

Fikse, W. F., and G. Banos. 2001. Weighting factors of sire daughter information in international genetic evaluations. J. Dairy Sci. 84:1759-1767.

Forabosco, F., A. F. Groen, R. Bozzi, J. A. M. Van Arendonk, F. Filippini, P. Boettcher, and P. Bijma. 2004. Phenotypic relationships between longevity, type traits, and production in Chianina beef cattle. J. Anim. Sci. 82:1572-1580.

Forabosco, F., J. H. Jakobsen, and W. F. Fikse. 2009. International genetic evaluation for direct longevity in dairy bulls. J. Dairy Sci. 92:2338-2347.

Holstein Canada. 2011. Classification System. Accessed Jul. 14, 2011 https://www.holstein.ca/Lite/Aspx/ClassificationTheSystemLite. aspx.

ICAR. 2011. International agreement of recording practices. guidelines approved by the general assembly, Riga, Latvia, June 2010. International Committee for Animal Recording, Rome, Italy.

Interbull. 2011a. Genetic correlations. Conformation. April 2011. Appendix III. Accessed Apr. 20, 2011. http://www-interbull.slu.se/ conform/framesida-conf.htm.

Interbull. 2011b. Genetic evaluation. Conformation. April 2011. Accessed Apr. 20, 2011. http://www-interbull.slu.se/conform/framesida-conf.htm.

Interbull. 2011c. Service documentation. Genetic estimation procedure. Accessed Jun. 29, 2011. http://www.interbull.org/images/stories/ Genetic_correlation_estimation_procedure_2009t2_110110.pdf.

Jakobsen, J. H., and E. Hjerpe. 2006. Interbull checks of incoming data. Interbull Bull. 34:11-15.

Klei, L., T. Mark, F. Fikse, and T. Lawlor. 2002. A method for verifying genetic evaluation results. Interbull Bull. 29:178-182.

Klei, L., and K. A. Weigel. 1998. A method to estimate correlations among traits in different countries using data on all bulls. Interbull Bull. 17:8-14.

Lawlor, T. J., and B. Klei. 2008. Results of the pilot study for body condition score and locomotion. Interbull Bull. 38:96-100.

Leitch, H. W. 1994. Comparison of international selection indices for dairy cattle breeding. Interbull Bull. 10:1-7

Mark, T. 2004. Applied genetic evaluations for production and functional traits in dairy cattle. J. Dairy Sci. 87:2641-2652.

Miglior, F., B. L. Muir, and B. J. Van Doormaal. 2005. Selection indices in Holstein cattle of various countries. J. Dairy Sci. 88:12551263

Miglior, F., P. G. Sullivan, and B. J. Van Doormaal. 2004. Accuracy of MACE evaluation for composite type traits compared to prediction based on linear traits. Interbull Bull. 32:41-45.

Miglior, F., P. G. Sullivan, and B. J. Van Doormaal. 2007. Optimum use of MACE information to predict composite type traits. Interbull Bull. 37:102-106. 
Powell, R. L., and H. D. Norman. 2006. Major advances in genetic evaluation techniques. J. Dairy Sci. 89:1337-1348.

Roche, J. R., N. C. Friggens, J. K. Kay, M. W. Fisher, K. J. Stafford, and D. P. Berry. 2009. Invited review: Body condition score and its association with dairy cow productivity, health, and welfare. J. Dairy Sci. 92:5769-5801.

SAS Institute. 2008. SAS/STAT User's Guide. Version 9.2. SAS Institute Inc., Cary, NC.

Schaeffer, L. R. 1994. Multiple-country comparison of dairy sires. J. Dairy Sci. 77:2671-2678.

Schneider, M. del P., J. W. Dürr, R. I. Cue, and H. G. Monardes. 2003. Impact of type traits on functional herd life of Quebec Holstein assessed by survival analysis. J. Dairy Sci. 86:4083-4089.

Sewalem, A., G. J. Kistemaker, F. Miglior, and B. J. Van Doormaal. 2004. Analysis of the relationship between type traits and functional survival in Canadian Holsteins using a Weibull proportional hazards model. J. Dairy Sci. 87:3938-3946.

Shook, G. E. 2006. Major advances in determining appropriate selection goals. J. Dairy Sci. 89:1349-1361.

Sigurdsson, A., and G. Banos. 1995. Dependent variables in international sire evaluations. Acta Agric. Scand. A Anim. Sci. 45:209 217
Sigurdsson, A., G. Banos, and J. Philipsson. 1996. Estimation of genetic (co)variance components for international evaluation of dairy bulls. Acta Agric. Scand. A Anim. Sci. 46:129-136.

Sölkner, J., J. Miesenberger, A. William, C. Furst, and R. Baumung. 2000. Total merit indices in dual purpose cattle. Arch. Tierzucht. 43:597-608.

Sullivan, P. G. 1999. Appendix: REML estimation of heterogeneous sire (co)variances for MACE. Interbull Bull. 22:146-148.

Sullivan, P. G., B. Zumbach, J. W. Dürr, and J. H. Jakobsen. 2012. International genomic evaluations for young bulls. Interbull Bull. 44:87-94.

VanRaden, P. M., and P. G. Sullivan. 2010. International genomic evaluation methods for dairy cattle. Genet. Sel. Evol. 42:7.

WHFF. 2008. Documentation. Type harmonization. World Holstein Friesian Federation. Accessed Apr. 11, 2011. http://www.whff. info/info/typetraits/TypeHarmonisation_2009update.pdf.

White, J. M. 1974. Genetic parameters of conformational and managemental traits. J. Dairy Sci. 57:1267-1278.

Zumbach, B., J. Jakobsen, F. Forabosco, H. Jorjani, and J. Dürr. 2012. Data selection and pilot run on simplified genomic MACE (S-GMACE). Interbull Bull. 43:1-8. 